\title{
Boost NOx removal by perovskite-based catalyst in NSR-SCR diesel aftertreatment systems
}

\author{
Jon Onrubia-Calvo ${ }^{1}$, Beñat Pereda-Ayo ${ }^{1}$, Maitane Urrutxua ${ }^{1}$, Unai De-La-Torre ${ }^{1}$, and \\ Juan Gonzalez-Velasco ${ }^{1}$ \\ ${ }^{1}$ Universidad del País Vasco Facultad de Ciencia y Tecnología
}

April 29, 2020

\begin{abstract}
DeNO $\mathrm{x}_{\mathrm{x}}$ activity of $0.5 \% \mathrm{Pd}-30 \% \mathrm{La} 0.5 \mathrm{Ba}_{0.5} \mathrm{CoO}_{3} / \mathrm{Al}_{2} \mathrm{O}_{3}$ formulation is analysed in single-NSR and combined NSR-SCR systems, using response surface methodology (RSM). Operational maps are built for any combination of reaction temperature in the NSR and SCR beds and $\mathrm{H}_{2}$ concentration. A $4 \% \mathrm{Cu} / \mathrm{SAPO}-34$ is used as the SCR catalyst. Results for single-NSR allows tuning operational conditions in coupled NSR-SCR technology to maximize $\mathrm{NO}_{\mathrm{x}}-$ to- $\mathrm{N}_{2}$ conversion, with minimum $\mathrm{NH}_{3}$ and $\mathrm{N}_{2} \mathrm{O}$ productions. Control of $\mathrm{H}_{2}$ concentration and temperature in the NSR system allows generating the stoichiometric amount of $\mathrm{NH}_{3}$ to eliminate NOx slipping. The tuned coupled NSR-SCR system achieves high $\mathrm{N}_{2}$ yield under wide operational range $\left(\mathrm{T}=175-425{ }^{\circ} \mathrm{C} ; \mathrm{C}_{\mathrm{H}_{2}}=2-4 \%\right)$. Specifically, $\mathrm{N}_{2}$ yield reaches $92 \%$ when NSR and SCR catalysts work at $300{ }^{\circ} \mathrm{C}$ and $3 \%$ $\mathrm{H}_{2}$ is injected, with $\mathrm{NH}_{3}$ slip and $\mathrm{N}_{2} \mathrm{O}$ production nearly zero. This provides a promising alternative for $\mathrm{NO}_{\mathrm{x}}$ removal in diesel aftertreatment systems.
\end{abstract}

\section{Hosted file}

Manuscript_AIChE.docx available at https://authorea.com/users/316332/articles/446819-boost-noxremoval-by-perovskite-based-catalyst-in-nsr-scr-diesel-aftertreatment-systems
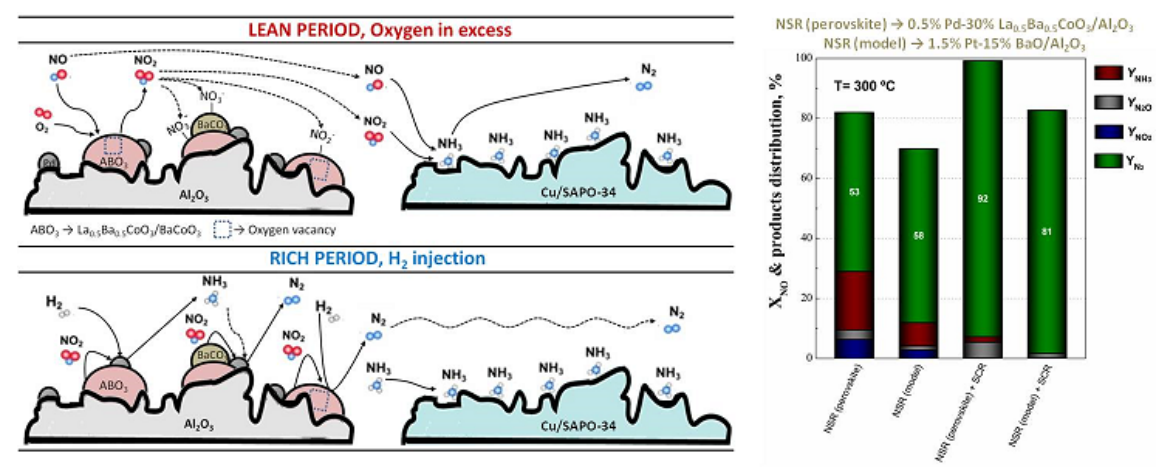


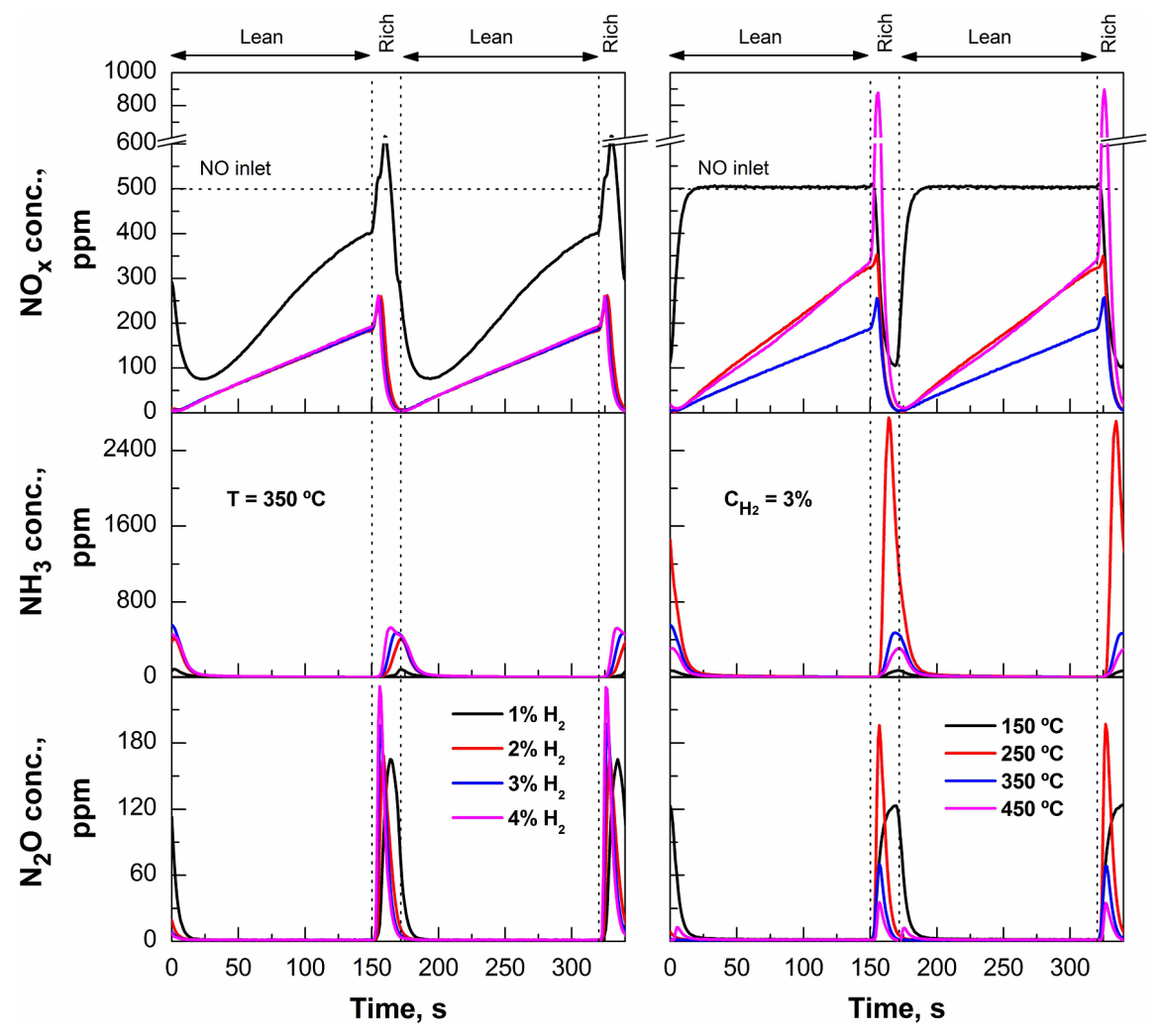



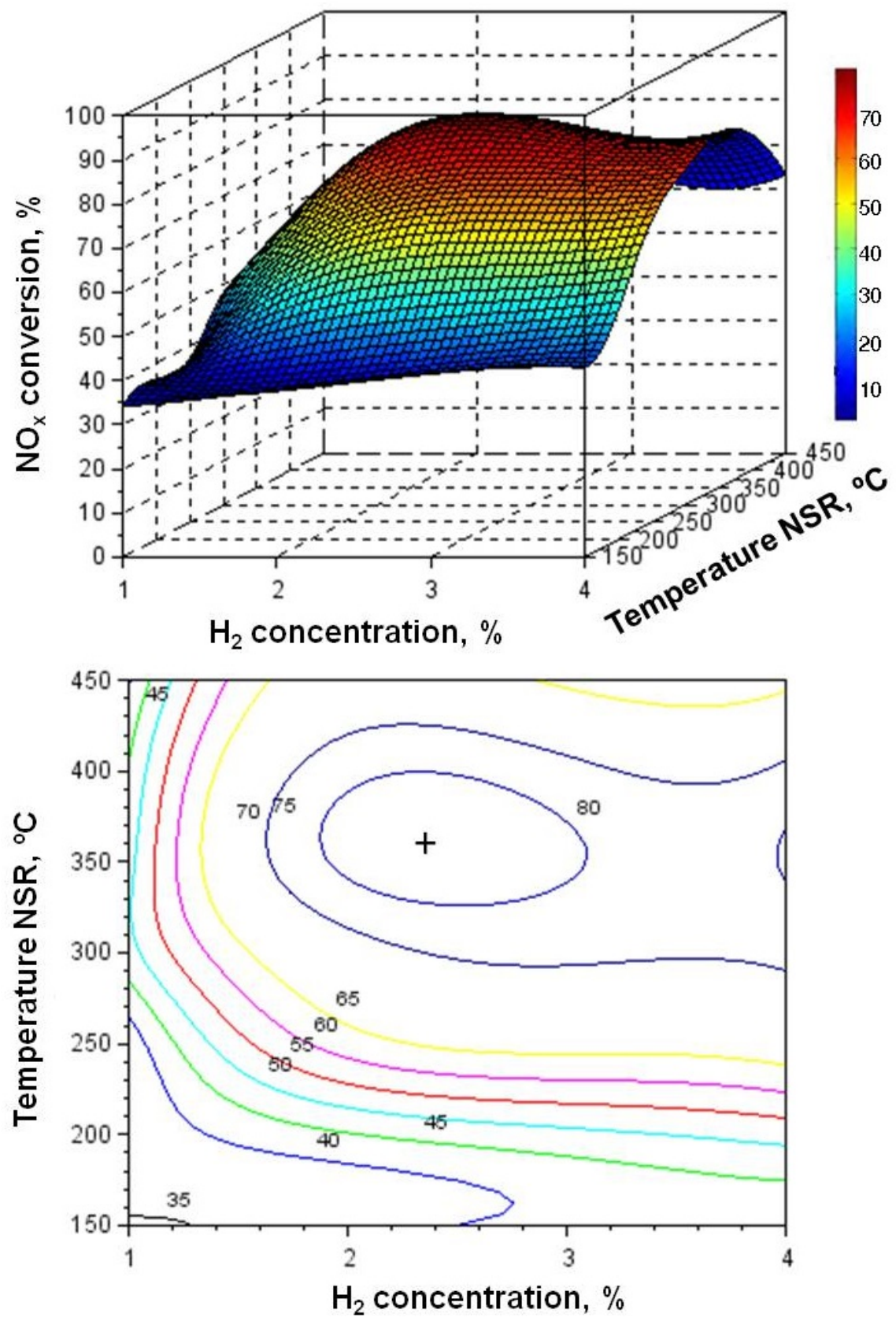

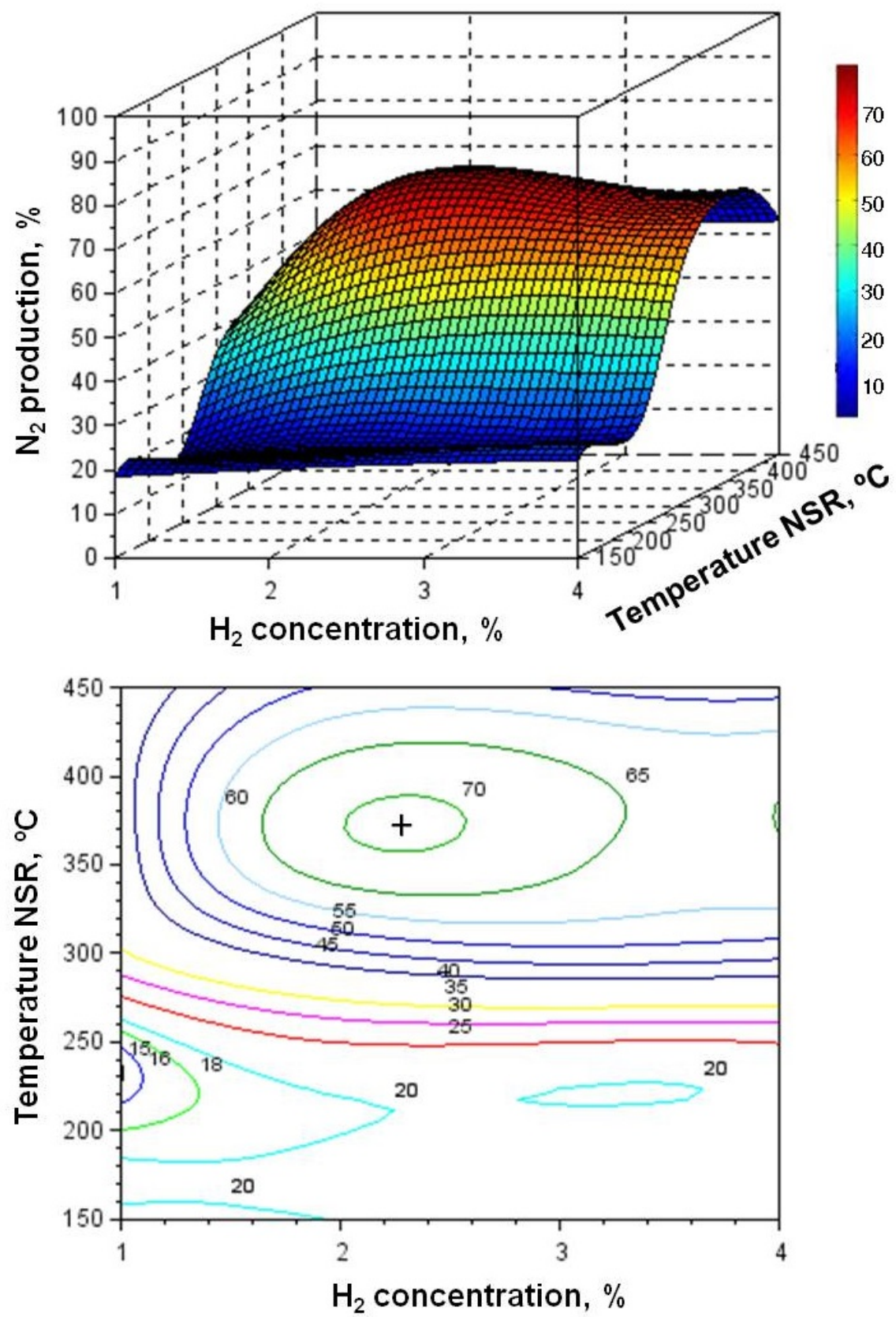

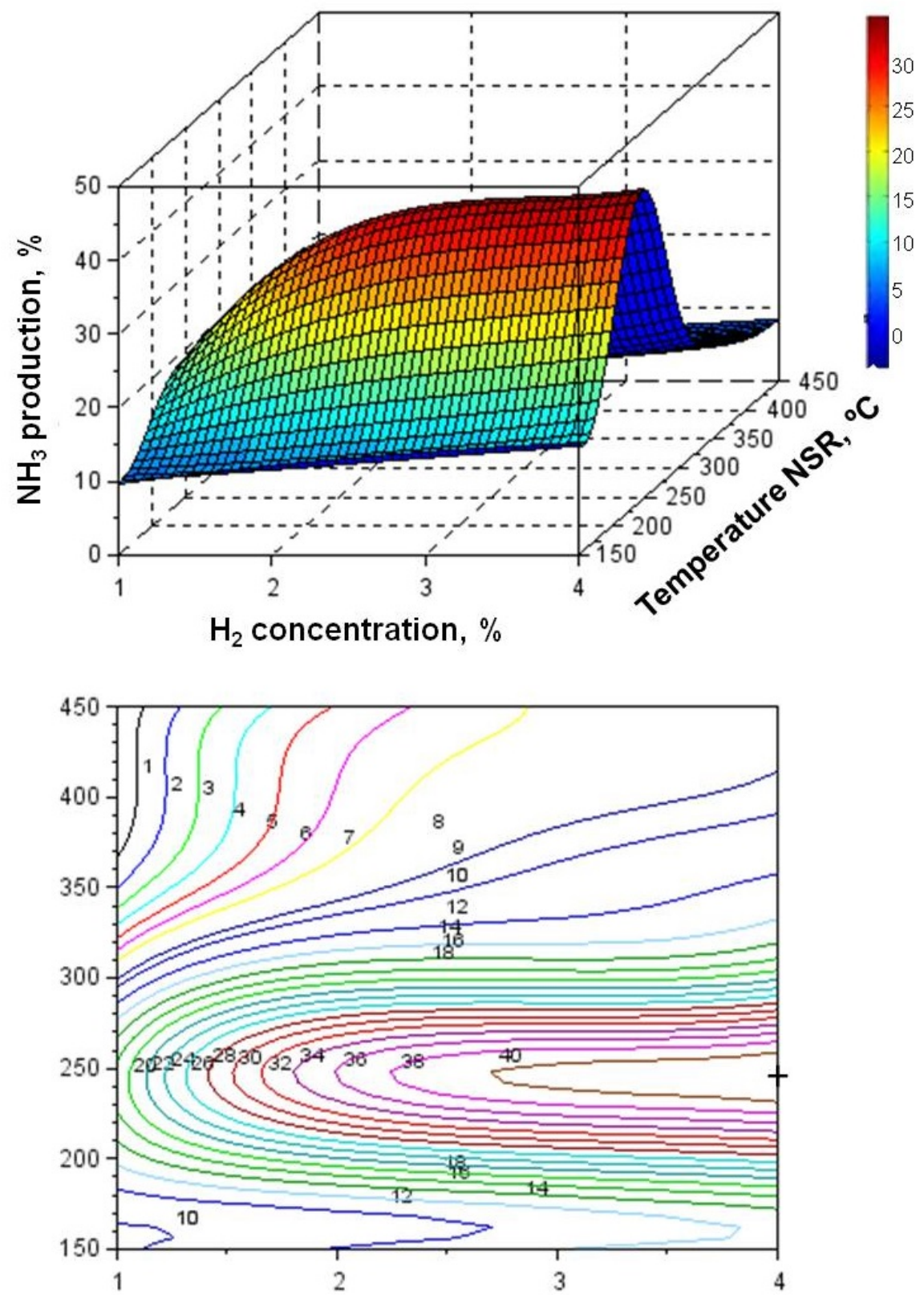

$\mathrm{H}_{2}$ concentration, \% 


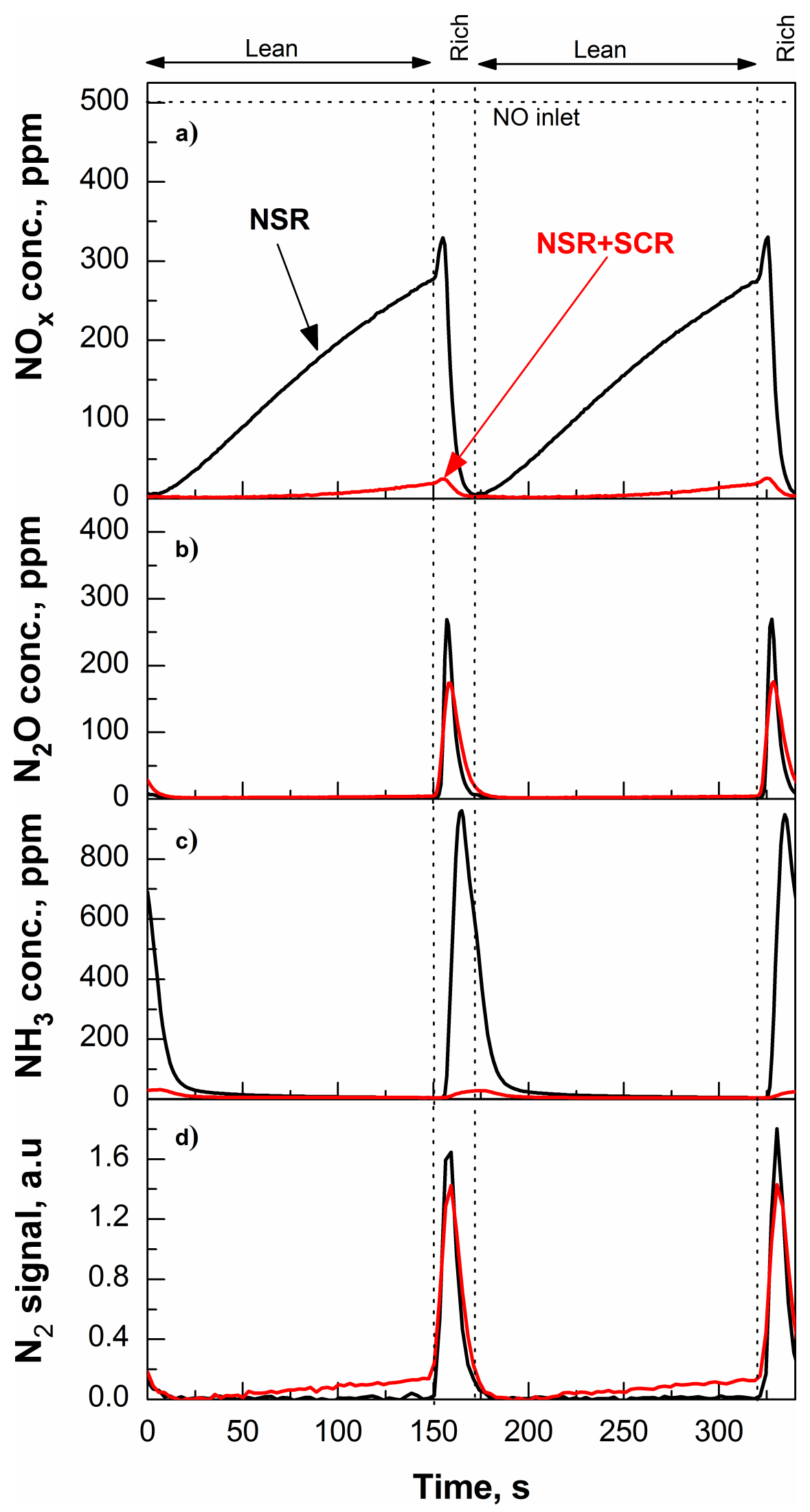




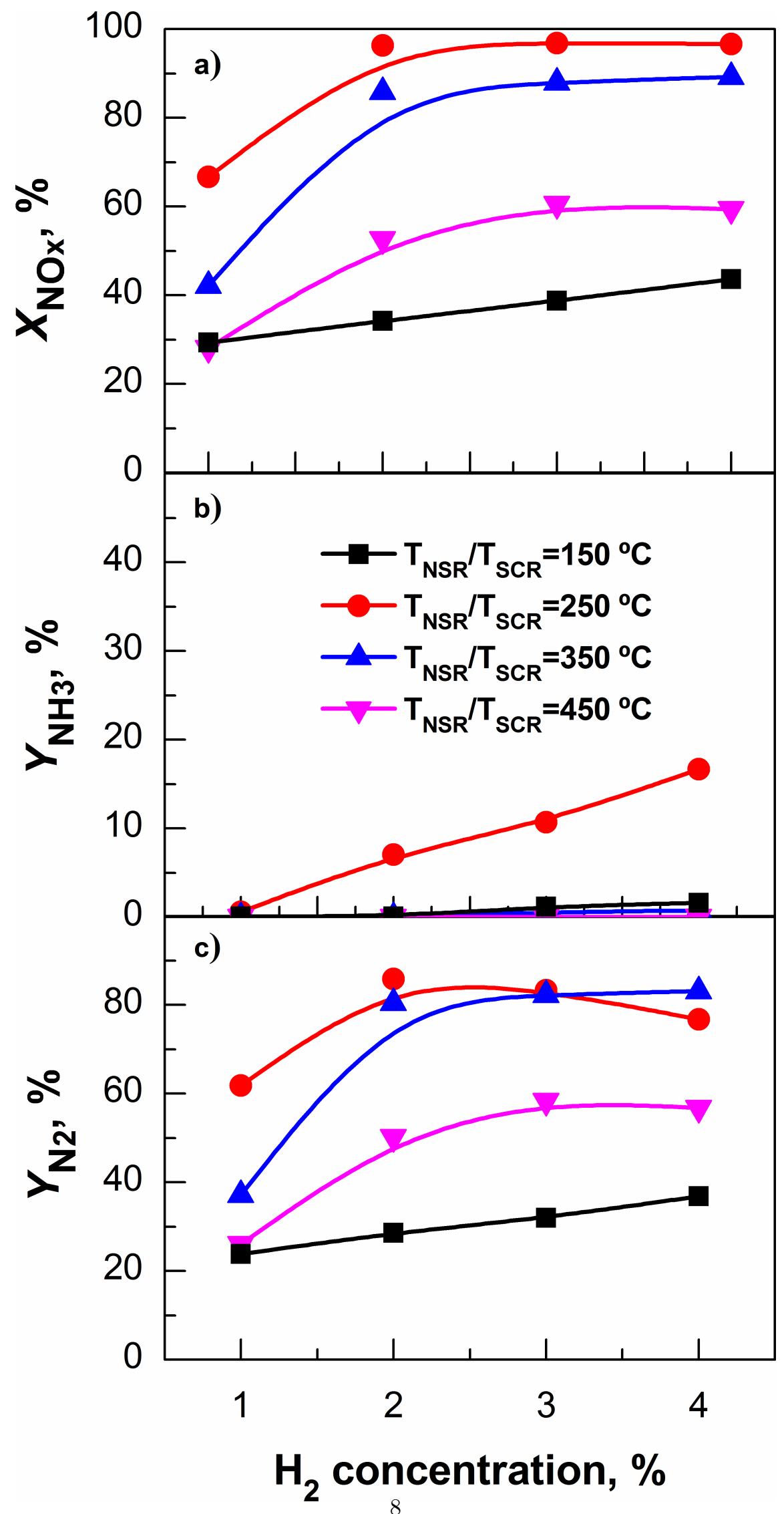



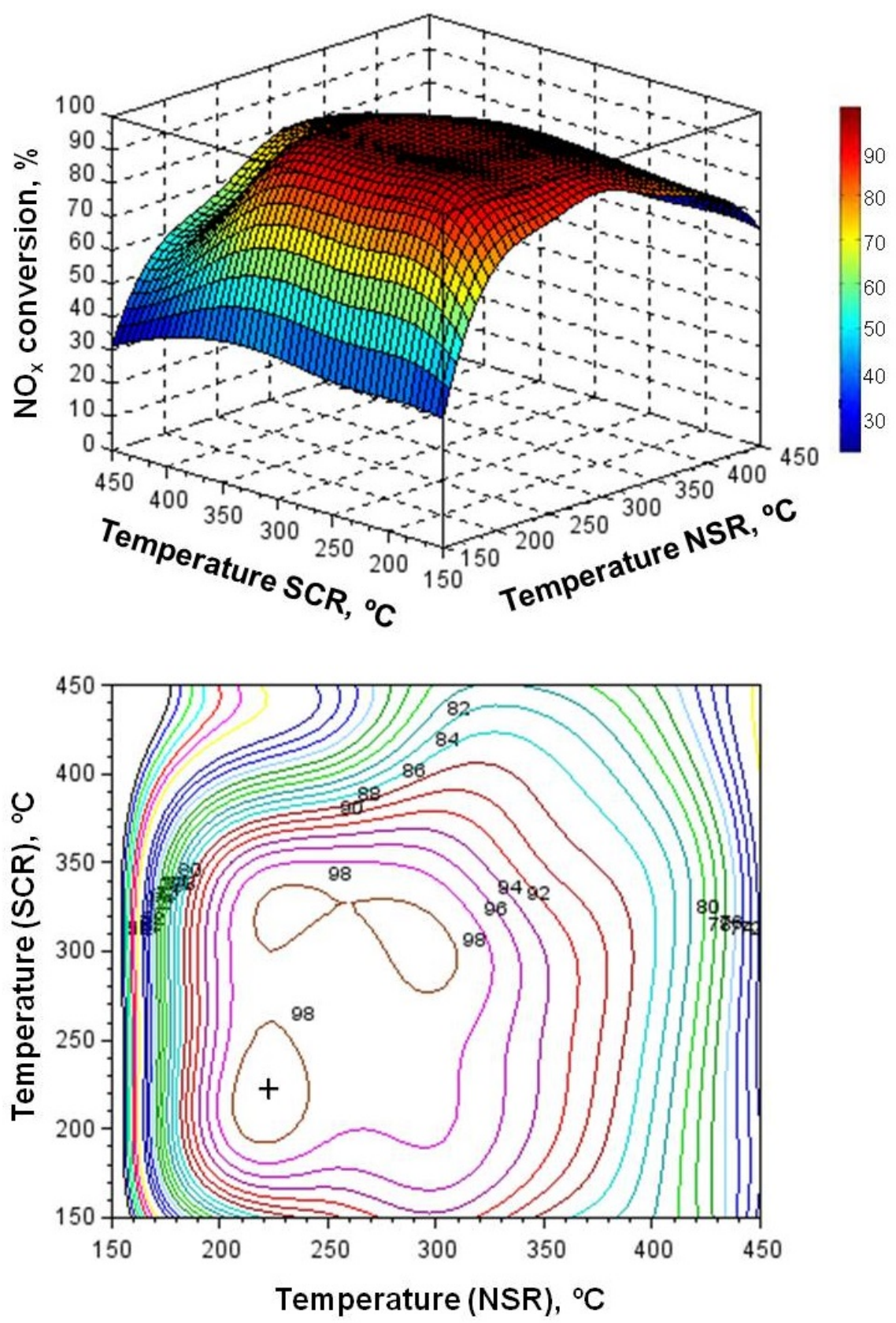

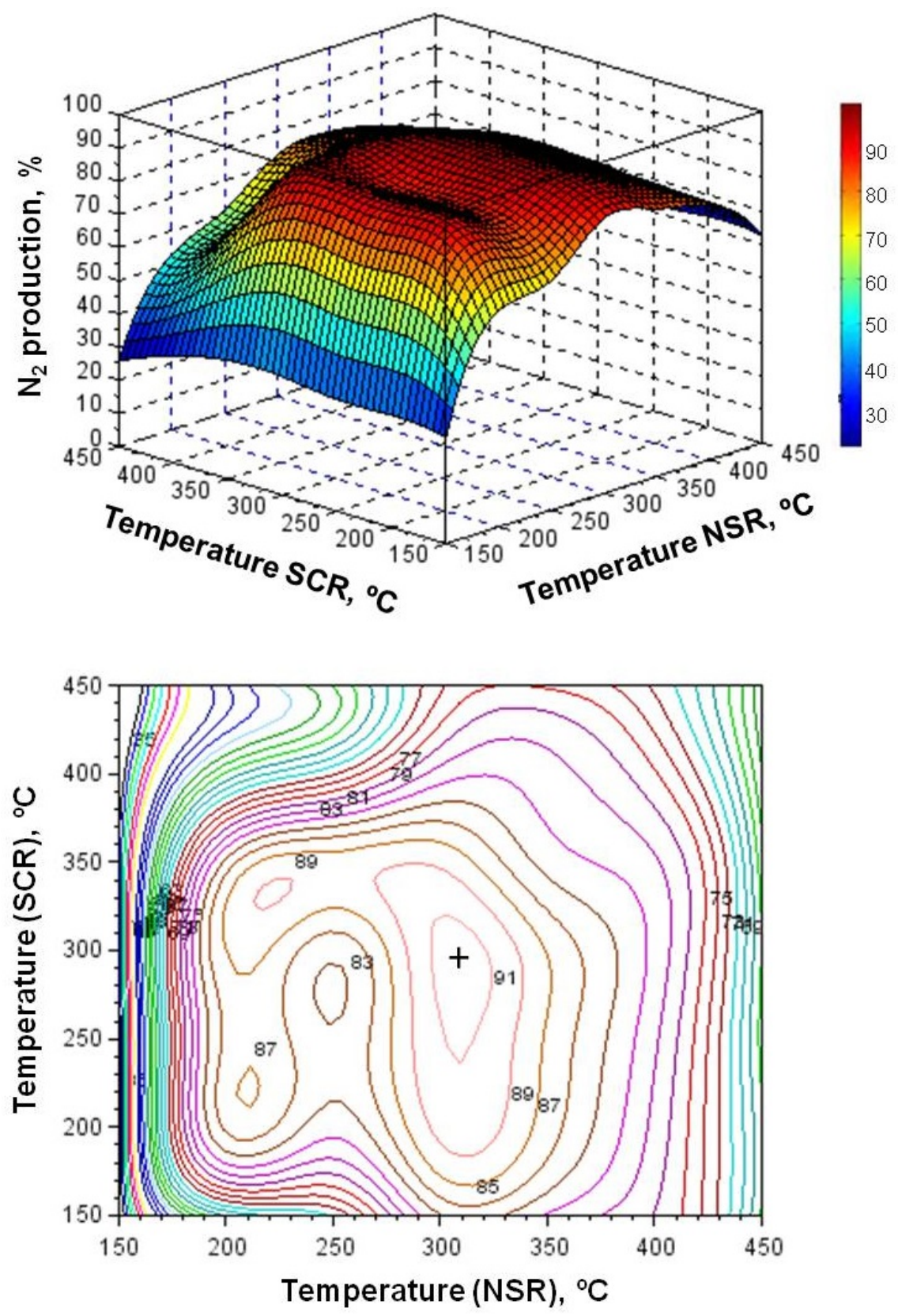

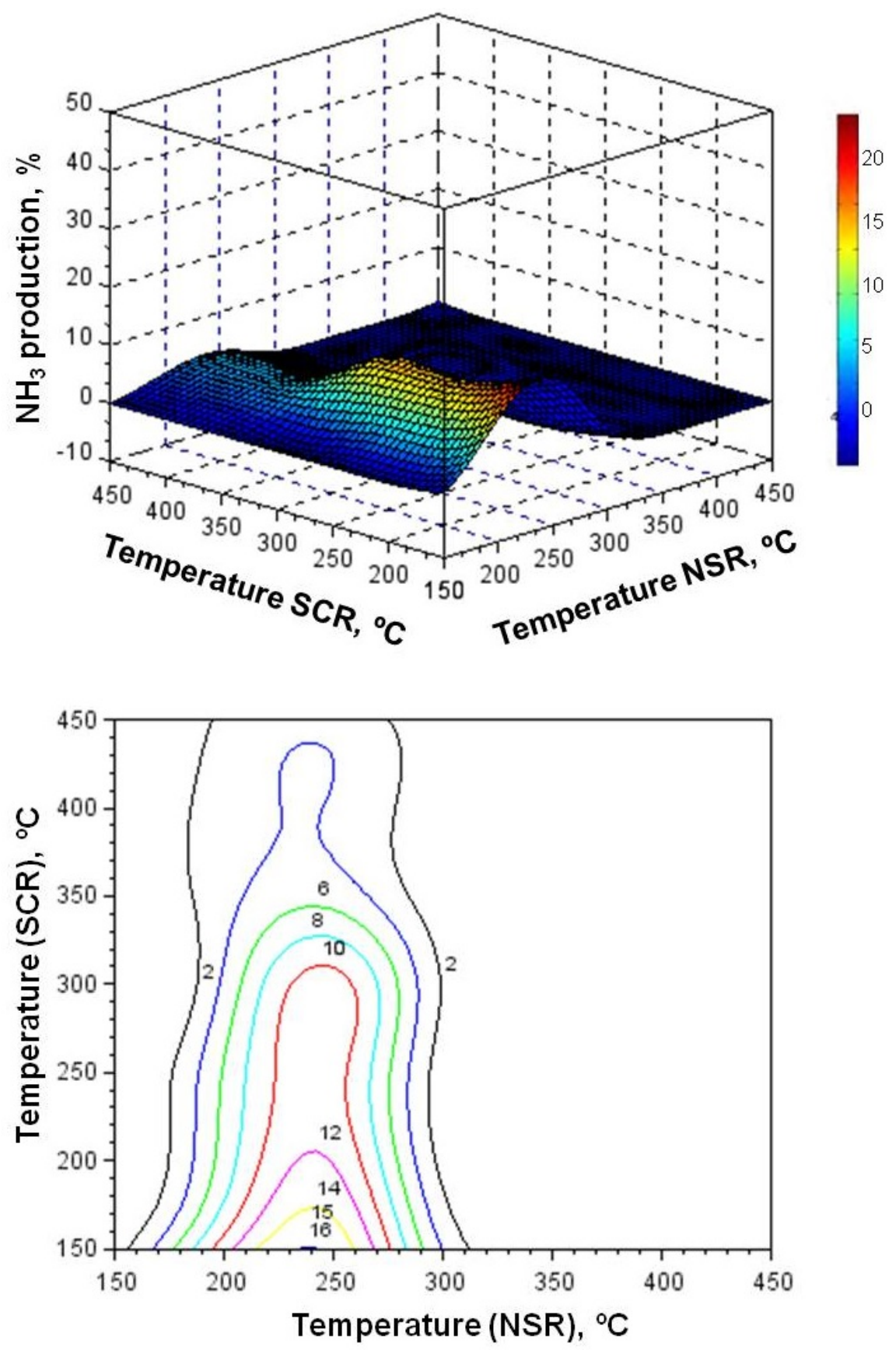


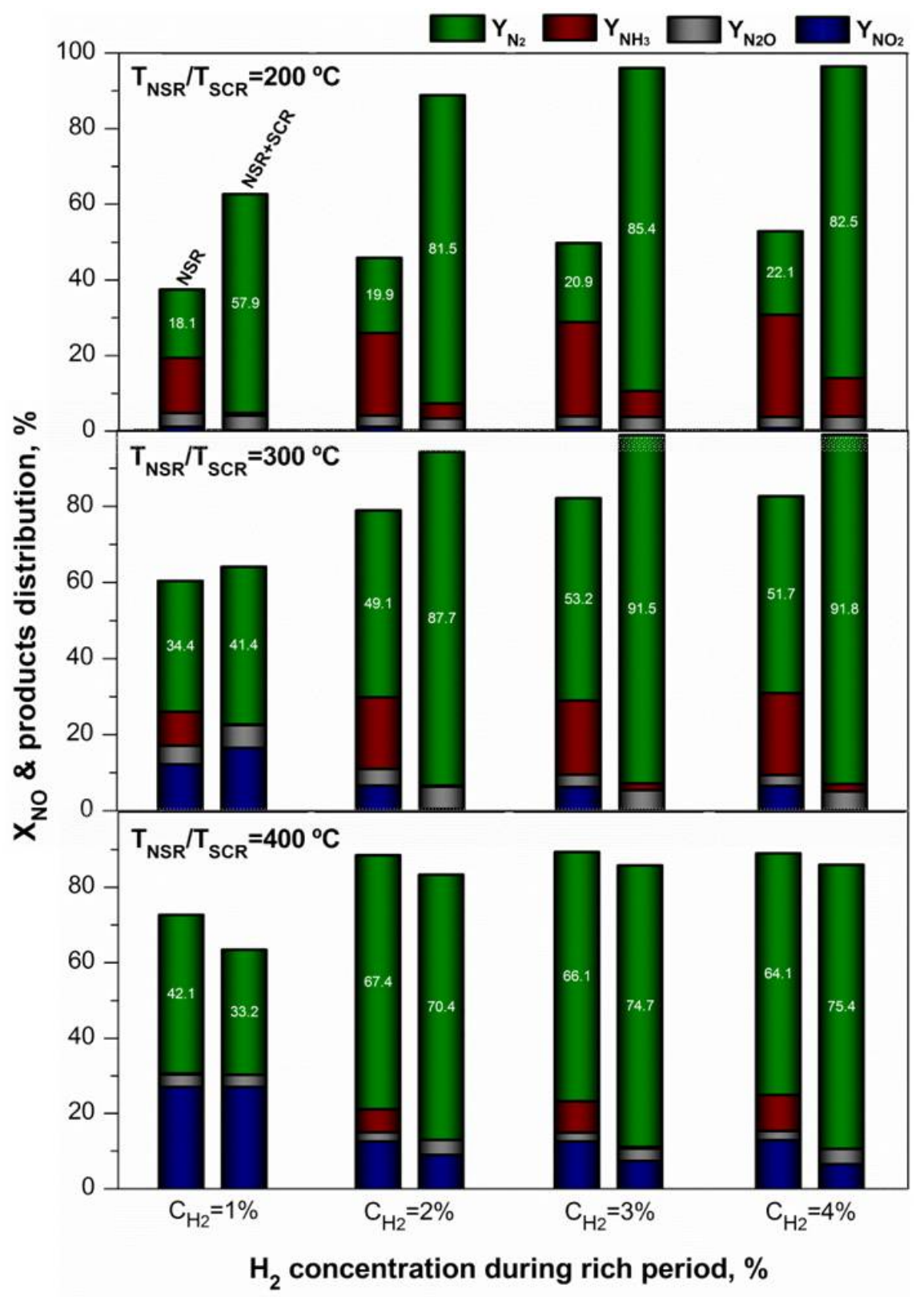

